\title{
Measure of Nitrogen in Special Steel
}

\author{
J. F. Curado, N. Added, M. A. Rizzutto, and M. H. Tabacniks \\ Pelletron Laboratory - DFN/IF - Universidade de São Paulo, \\ Caixa Postal 66318 - CEP 05315-970 - São Paulo - SP - Brazil
}

\section{Received on 11 August, 2005}

\begin{abstract}
Stainless steel is widely employed in different areas of modern industrial production, taking advantage of its corrosion resistance. In this work we use the elastic recoil detection analysis (ERDA) to determinate the profile of nitrogen in stainless steel samples. An incident beam of ${ }^{35} \mathrm{Cl}$ of $50 \mathrm{MeV}$ was used for the analysis of sample components. The results have indicated the presence of thin films in the surface of some analyzed samples and have allowed the determination of the concentration and the thicknesses of these films.
\end{abstract}

\section{INTRODUCTION}

The development in the area of material science has been very significant in the last years, with special emphasis in the microelectronics and metallurgy industries generating a parallel development in the area of analysis of materials due the necessity of better thickness definition of thin films and the depth profile of composites deposited on thick substrate.

The characterization of special steel samples, in special the profile of nitrogen, aims to improve the quality of the surface and to increase the durability of steel pieces. In this work, the samples have been characterized through ERDA [1,2], getting the profile of the nuclei of the constituent elements in samples from the analysis of the energy spectra.

The method ERDA has high efficiency for the identification and quantification of materials with light elements in heavy elements matrix (lighter than $\mathrm{Ne}$ ) [3, 4]. Using heavy elements projectiles and a $\Delta E-E$ detection system $[1,2,5-$ 8], this method has the advantage of high sensibility for the atomic number identification, thereby being applicable for the elementary analysis of thin films deposit on heavy element substrates $[9,10]$.

\section{EXPERIMENTAL}

The experimental setup was mounted in the scattering chamber at $30^{\circ}$ beam line of the 8UD Tandem accelerator of the Pelletron Laboratory of the University of So Paulo. An ionization chamber was positioned at $40^{\circ}$ with respect to the beam direction and the sample holder was set in a way that the angle between the normal direction related sample surface and the incident beam was $60^{\circ}$. The ionization chamber, with a polypropylene beam entrance window of $80 \mu \mathrm{g} / \mathrm{cm} 2$, uses P10 mixture (90\% argon and 10\% methane) with 17 Torr of pressure. For the measurements, an incident beam of $50 \mathrm{MeV}$ $\mathrm{Cl}^{7+}$ ions was used.

The data acquisition was a home mode one. That allows to check the experience through display of the spectrums. The digitalized information corresponding to $E$ and $\Delta E$ of the recoil particles was stored in the event mode during the acquisition. The elementar composition relative to $\mathrm{Fe}$ was calculated taking in account the difference in their scattering cross- section. This composition was simulated and compared using the specific code SIMNRA[11].

The samples analyzed consist of small discs, with $15 \mathrm{~mm}$ of diameter and $6 \mathrm{~mm}$ of height. Each sample was treated in different conditions using plasma for addiction of nitrogen. The samples were given by Antonio Jorge Abdalla, researcher of Diviso de Fotoionica do IEAv (Instituto de Estudos Avanados).

\section{RESULTS AND DISCUSSION}

An $E$ versus $\Delta E$ spectrum for one of the samples is shown in figure 1. In this spectrum can be clearly identify the presence of thin films in the surface of analyzed sample. The area for each element was selected and projected on the E axis to compare with SIMNRA simulations.

Analysis of all samples allows the identification of two groups: a) samples with thinner oxide film on the surface and a smaller carbon contribution in the bulk; b) samples with wider oxide film on the surface and a bigger carbon contribution in the bulk.

Figures 1 and 2 shows the energy spectrum for carbon, nitrogen and oxygen particles for different samples. The composition ratios were estimated using the integrated the area for each element.

Figure 3 shows the results from simulation using SIMNRA for fitting energies spectra for each element.

\section{CONCLUSIONS}

The experimental procedure using this ERDA system has enough resolution for the identification of light elements presents in the surface of the samples.

However results show a limitation of few $\mathrm{mm}$ for the depth profile due to energy restriction related to the stopping power of the ions in steel.

Subsequently, we plan to obtain a deeper profile nitrogen for the same samples, using others experimental techniques as PIGE (Particle Induced Gamma Ray Emission), and NRA (Nuclear Reaction Analysis). 

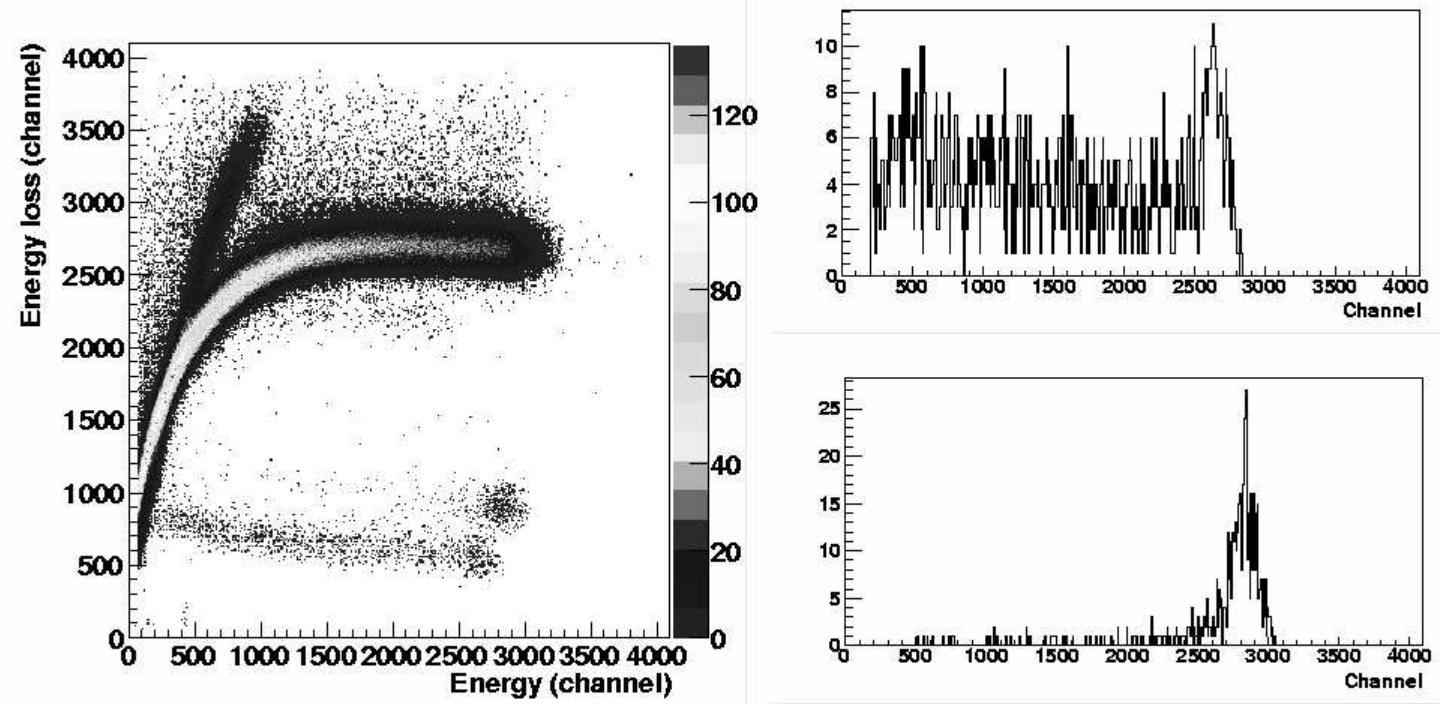

FIG. 1: Show biparametric spectra for sample with a small contribution of oxygen and carbon on surface and the projection on the Energy axis.
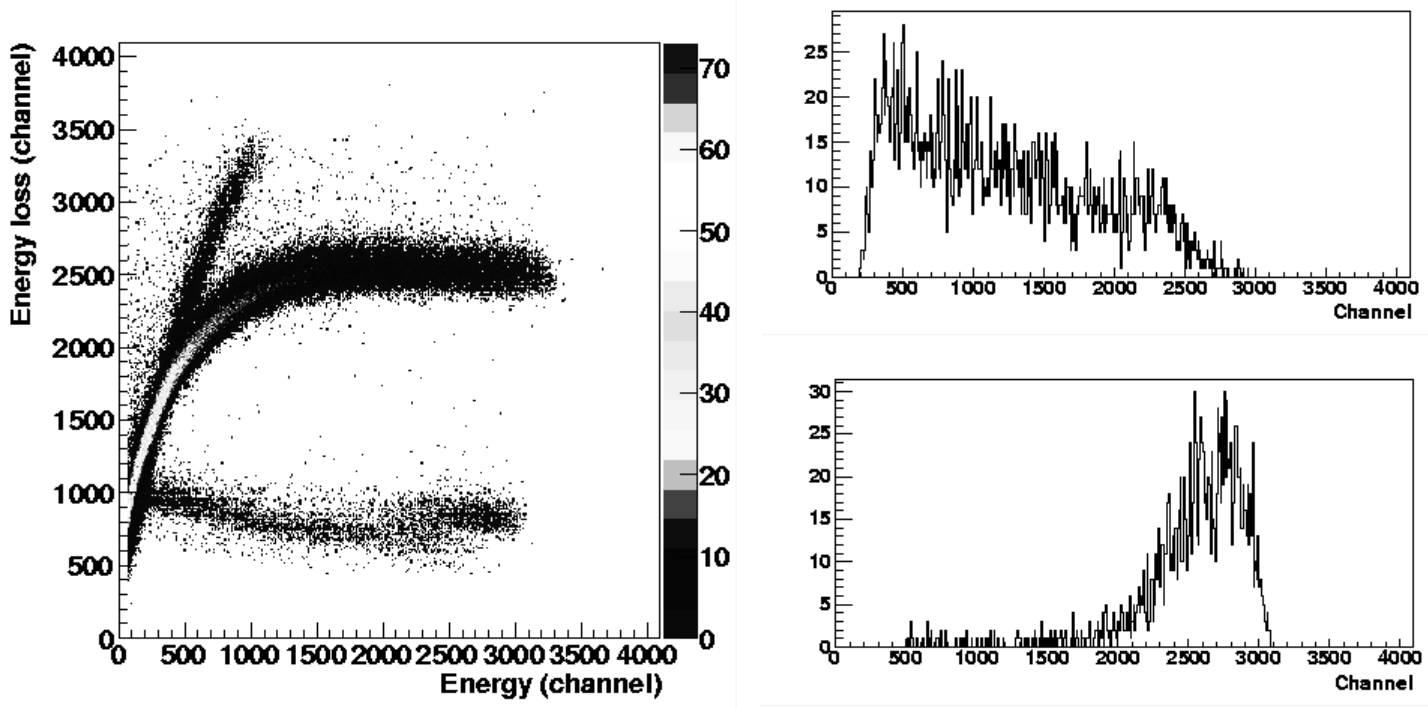

FIG. 2: Shows biparametric spectra with carbon and oxygen contribution on surface and the projection on the Energy axis.

\begin{tabular}{|c|c|c|c|c|c|}
\hline & Elem & Concentration & & Elem & Concentration \\
\hline \hline \multirow{2}{*}{ Layer 1 } & $\mathrm{C}$ & $0,0438 \pm 0,0034$ & Layer 1 & $\mathrm{C}$ & - \\
$600 \times 10^{15}$ & $\mathrm{~N}$ & $0,00245 \pm 0,00076$ & $1600 \times 10^{15}$ & $\mathrm{~N}$ & - \\
atoms $/ \mathrm{cm}^{2}$ & $\mathrm{O}$ & $0,0470 \pm 0,0070$ & $\mathrm{O}$ & $0,2975 \pm 0,0096$ \\
& $\mathrm{Fe}$ & $0,9067 \pm 0,0095$ & atoms $/ \mathrm{cm}^{2}$ & $\mathrm{Fe}$ & $0,702 \pm 0,017$ \\
\hline & $\mathrm{C}$ & $0,00793 \pm 0,00098$ & & $\mathrm{C}$ & $0,00793 \pm 0,00098$ \\
Layer 2 & $\mathrm{N}$ & $0,00214 \pm 0,00064$ & Layer 2 & $\mathrm{N}$ & $0,1927 \pm 0,0076$ \\
Bulk & $\mathrm{O}$ & $0,00000 \pm 0,00002$ & Bulk & $\mathrm{O}$ & $0,00325 \pm 0,00064$ \\
& $\mathrm{Fe}$ & $0,990 \pm 0,011$ & & $\mathrm{Fe}$ & $0,793 \pm 0,020$ \\
\hline
\end{tabular}

TABLE I: Final concentration values for each element of analyzed samples. Table a) shows results for samples that contains a thin film of Oxygen on the surface. Table b) shows results for samples that contains also a Carbon contribution in the superficial film. 

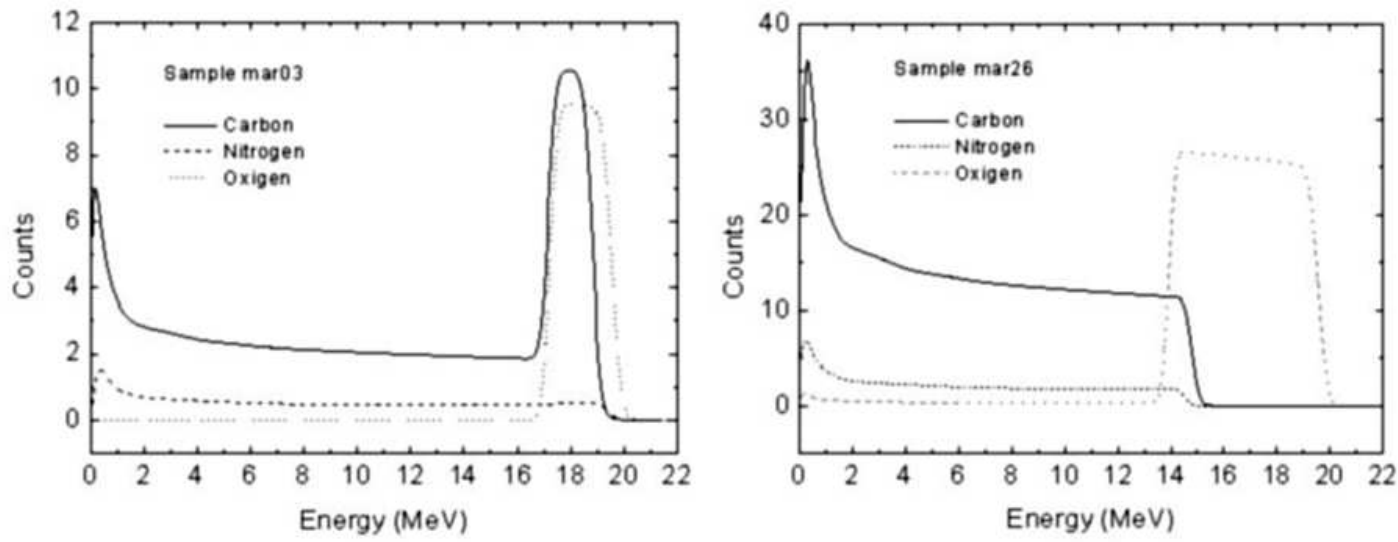

FIG. 3: Simulated energy spectrum using program SIMNRA using a ${ }^{35} \mathrm{Cl}$ beam with $\mathrm{E}_{\text {Lab }}=50 \mathrm{MeV}$ for the samples mentioned in table above: figure a) thin film of $\mathrm{FeO}$ with thickness of $1600 \times 10^{15} \mathrm{atoms} / \mathrm{cm}^{2}$; figure b) shows thin film (FeOCN) with thickness of $600 \times 10^{15} \mathrm{atoms} / \mathrm{cm}^{2}$.

[1] J. Lecuyer, C. Brassard, C. Cardinal, J. Chabbal, L. Deschenes, and J. P. Labrie, J. Appl. Phys. 47, 381 (1976).

[2] E. Arai, A. Zounek, M. Sekino, K. Takemoto, and O. Nittono, Nucl. Instr. and Meth. B 85, 226 (1994).

[3] R. J. Girnius, L. W. Anderson, Nucl. Instr. and Meth B 36, 283 (1996).

[4] W. Bohne, G. U. Reinsperger, J. Rüschert, B. Selle, and P. Staub, Nucl. Instr. and Meth B161-163, 467 (2000).

[5] N. Dytlewski, P. J. Evans, J. T. Noorman, L. S. Wielunski, and J. Bunder, Nucl. Instr. and Meth B118, 278 (1996).

[6] Y. Wang, B. Huang, D. Cao, D. Zhu, and K. Shen, Nucl. Instr. and Meth B84, 111 (1994).
[7] W. Assmann, J. A. Davies, G. Dollinger, J. S. Forster, H. Huber, T. Reichelt, and R. Siegele, Nucl. Instr. and Meth B 118, 424 (1996).

[8] R. Siegele, W. Assmann, J. A. Davies, and J. S. Forster, Nucl. Instr. and Meth B 118, 283 (1996).

[9] W. Hong, S. Hayakawa, K. Maeda, S. Fukuda, M. Yanokura, M. Aratani, K. Kimura, Y. Gohshi, and I. Tanihara, Nucl. Instr. and Meth B 124, 95 (1997).

[10] J. Tirira, P. Trocellier, and J. P. Frontier, P. Trouslard, Nucl. Instr. and Meth B 45, 203 (1990).

[11] M. Mayer, SIMNRA User's Guide 